\title{
EXPERIMENTAL VALIDATION OF EFFECT OF EQUIVALENCE RATIO ON DETONATION CHARACTERISTICS OF PROPANE/OXYGEN MIXTURES
}

\author{
P. Srihari, G. Sai Krishna Prasad, Dr. B.V.N. Charyulu, Dr. D.N. Reddy* \\ Scientists, Defence Research \& Development Laboratory (DRDL), DRDO, Min. of \\ Defence, Hyderabad \\ *Prof. (Retd), Osmania University, Hyderabad, India
}

\begin{abstract}
:
Experimental studies were carried out for using Propane as fuel for Pulse Detonation Engine application. In the present study Detonation Characteristics of Propane \& Oxygen mixture at various equivalence ratios were presented. In these experiments Propane and Oxygen under regulated pressures were injected into a Detonation Tube from the head end using unlike impinging doublet injector. The fuel and oxidizer were allowed to mix and fill the tube. Subsequently, the mixture was ignited using a spark plug positioned close to the head end of the tube. The pressures generated due to the combustion of the mixtures were captured using five high frequency pressure transducers which were spaced 100mm apart on the detonation tube. Apart from these pressures, velocities of the combustion wave were computed using 'time of flight' method. These tests were done for different equivalence ratios varying from 0.8 to 1.6 by varying the feeding pressure of Propane. In the present study the performance of the combustion wave at different locations and effect of equivalence ratios on detonation characteristics were presented. In addition effect of presence of obstacles in the flow path i.e., Shchelkin spirals were also studied in reducing the Deflagration to Detonation Transition (DDT) distance.
\end{abstract}

Index Terms: Pulse Detonation, Propane, Injector, Equivalence Ration, Shchelkin Spiral, DDT. I. INTRODUCTION

The need for faster flight, keeping fuel efficiency has propelled researcher's inventive thinking into realms beyond imagination. Since the days of the Wright brothers, aircraft propulsion has come a long way. The invention of the gas turbine, and decades of research on it, has made the gas turbine a very effective source of power for air transportation, with very high fuel efficiency. The introduction of ramjet engines propelled airplanes to break the sound barrier with ease and became the main force for all the tactical missile applications. The latest in propulsion is the scramjet engine, where the design of a ramjet was improved to reduce losses from the shock waves made possible the historic X-43A hypersonic flight in March 2004.

An advanced propulsion system that is being researched is the Pulse Detonation Engine. This system has the ability to take-off without any auxiliary propulsion system from low to high mach and to cross the hypersonic barrier with highly fuel efficient manner.

Pulse detonation engines (PDEs) have emerged as potential devices to better utilize the chemical energy content of reactive fuel/air mixtures. One of the main advantages of PDEs is that detonations create less entropy when they combust a fuel/air mixture than conventional constant pressure combustion processes such as those used in current gas turbines, resulting in a more 
efficient thermodynamic cycle. Establishing whether PDEs can achieve higher operating efficiency than conventional propulsion systems (i.e. gas turbines, ramjets, etc) is the focus of many research groups around the world.

\section{OBJECTIVE}

\section{A. Pulse Detonation Engine}

A detonation is a supersonic combustion wave that typically propagates at a few thousand meters per second relative to an unburned fuel/air mixture. Detonation is a much more energetic phenomenon than deflagration and produces higher pressures. A detonation wave compresses a fluid, increasing its pressure and density, in addition to increasing its temperature. Detonations can be approximated as supersonic shock waves that initiate and closely coupled to a thin flame front or combustion region. Due to the high speed nature of a detonation wave, detonation closely approximates a constant volume combustion process as compared to a constant pressure of Brayton cycle.

Pulse detonation engines (PDEs) have received considerable attention over the past three decades. These devices use detonation waves that propagate through a premixed fuel-air mixture and produce large chamber pressures and, thereby, thrust.

PDEs offer the potential for high performance because the rapid detonation process results in constant volume combustion with very high operating frequencies and combustor chamber pressures. PDEs are predicted to be very efficient and offer good thrust characteristics from the low subsonic to the high supersonic flight regimes. PDEs also have the potential to operate at very high energy densities, allowing the use of simple and compact combustor designs.

\section{B. Basics of Pulse Detonation Engine (PDE)}

The basic PDE has a very simple structure, as seen in Fig.1, consisting of a constant area tube, with valves to control the supply of fuel and oxidizer, an ignition system, and a nozzle for accelerating the flow if the engine is to be applied for propulsion. A practical PDE may also have one or more devices to bring about deflagration to detonation transition (DDT), such as a Shchelkin spiral. The PDE cycle has four stages, namely fill, combustion, blow down (exhaust) and purge. The four stages are presented in Fig.2.

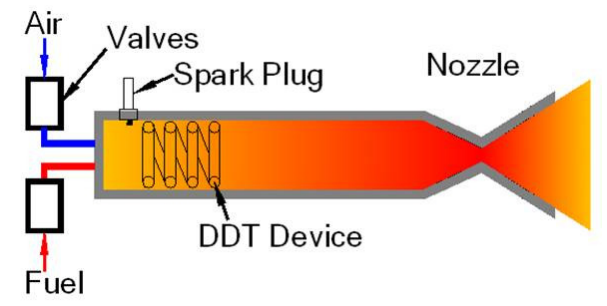

Fig.1 Schematic of Basic Pulse Detonation engine with valves at inlet and nozzle at exit 
The PDE combustion chamber is filled with fuel and oxidizer during the fill stage. When the fuel-oxidizer mixture is filled to the required volume, the combustion stage commences when a spark is fired to start ignition. A detonation wave is soon created that moves through the mixture and causes the pressure and temperature behind it to rapidly shoot up. The next stage is the blow down stage, when a series of rarefaction waves travel upstream into the combustion chamber and reflect off the end wall, causing the high pressure burnt gases to exit the combustion chamber at a high speed. This is then followed by the purge stage, when fresh air is blown through to clean and

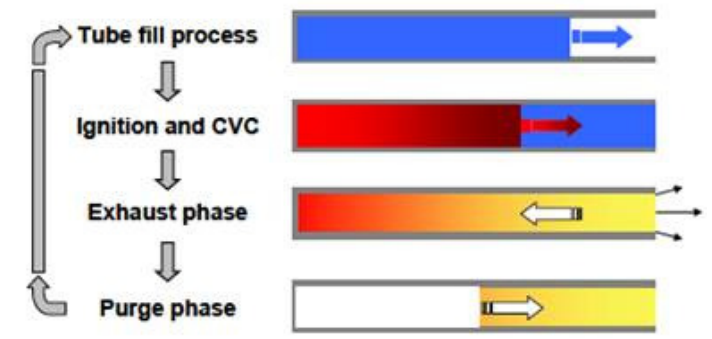

cool the tube before the fill stage starts again.

Fig.2. Pulse Detonation engine Cycle

\section{Scope of the Present Paper}

This paper describes the basic characteristics of gaseous detonations. A test setup was established to study the various factors influencing the detonation of gaseous fuel Propane with Oxygen. Experiments were conducted to study the effect of equivalence ratio on detonation characteristics like CJ pressures and velocities. In addition tests were conducted to study the DDT by using Shchelkin spirals with different blockage ratios (BR).

\section{EXPERIMENTAL SETUP}

\section{A. PDE Tube Configuration \& Test Setup}

The experiments were carried out using single detonation tube. The test setup layout is shown in Fig.1. The total tube is made from 4 sections. First section which is $150 \mathrm{~mm}$ in length is having provision for mounting the spark plug. A conventional doublet injector is designed for supplying the fuel and oxidizer in to the tube. Second section is $450 \mathrm{~mm}$ in length. This section is having provision for inserting the DDT device i.e, Shchelkin spirals. Pressure transducer mounting points are provided at $100 \mathrm{~mm}$ distance a part. Third and Fourth sections are of $200 \mathrm{~mm}$ and $300 \mathrm{~mm}$ in length with Pressure transducer mounting points.

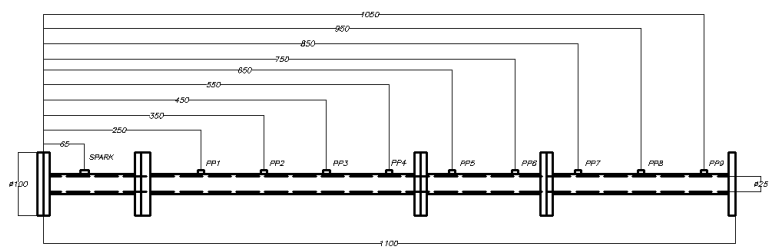

Fig.3. Dia 25mm PDE Tube Configuration 

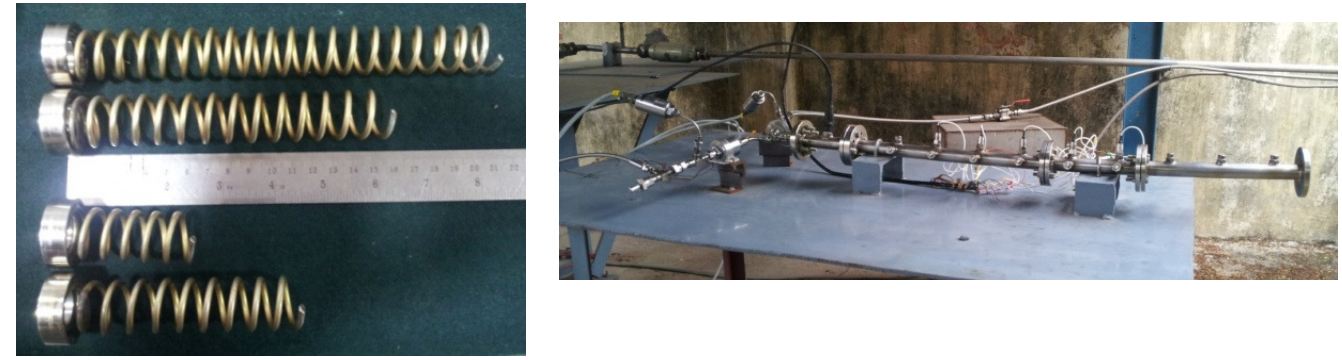

Fig.4. Dia 25mm PDE Test setup \& Shchelkin Sprirals

\section{B. Propellant Feed System and Ignition}

The Propane and Oxygen are supplied to the PDE tube through electrically operated direct acting Solenoid Valves. To get the required equivalence ratio, upstream pressures are controlled by using Pressure Regulators. The mass flows are calibrated using pre calibrated orifices placed in the injector line. The following picture shows the injector configuration.
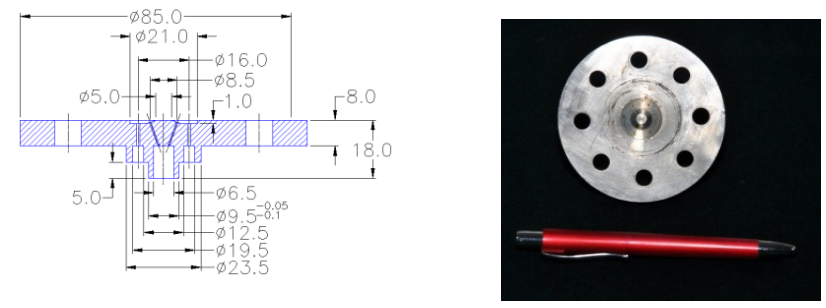

Fig.5. Injector Configuration

The solenoid valves used for flow control are directing type. They operate with 24V DC current. The response times of the valves are $15 \mathrm{msec}$. The solenoid valves are kept in on condition for $5 \mathrm{sec}$ such that the tube is filled and command is issued to the spark plug. The following picture shows the details of Spark Plug unit.

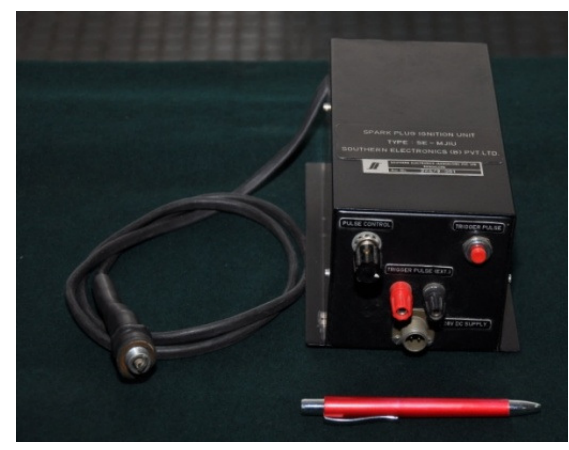

Fig.6. Spark Ignition System

The spark ignition system works with AC power supply. It generates around 2J. When switched on it maintains the spark for a period of $0.8 \mathrm{msec}$.

\section{Instrumentation \& Data Recording}

High response transducers are used for pressure pickup. These pressure transducers are having 
$100 \mathrm{~K}$ sampling rate. As the pressure peeks are of the order of micro second, these sensors will be able to pickup Von Newman spike pressures very accurately.

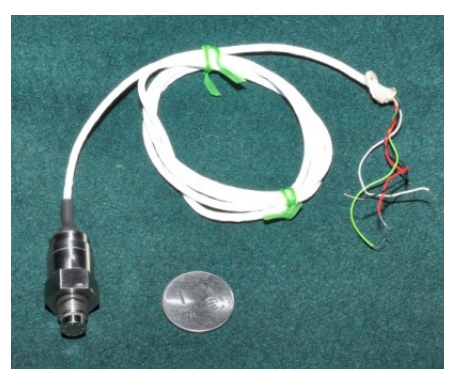

Fig.7. Pressure Transducer

The date recording is dome through National Instruments data acquisition system. The system is capable of programming the events like Solenoid valves ON/OFF and Spark Plug ON. The exact timings also can be controlled to the order of one micro second.

\section{TEST RESULTS}

Series of experiments were carried out using Propane as fuel and Oxygen as oxidiser. The equivalence ratio $(E R)$ is varied from 0.8 to 1.6 in steps of 0.2 . The pressures were recorded using 5 nos of pressure transducers. They are placed at $250 \mathrm{~mm}, 350 \mathrm{~mm}, 450 \mathrm{~mm}, 550 \mathrm{~mm}, 650 \mathrm{~mm}$ from the injector plane. Based on the Pressure Transducer location we can find out at what distance the detonation is occurring.

\section{A. Experiments without DDT (Shchelkin Spirals)}

First set of experiments were carried out with propane and oxygen without any DDT enhancing devices. The following Fig. show the pressures recorded during the tests. The units of pressure are $\mathrm{Kg} / \mathrm{cm}^{2}(\mathrm{Ksc})$. Five runs were taken with ER value ranging from 0.8 to 1.6.

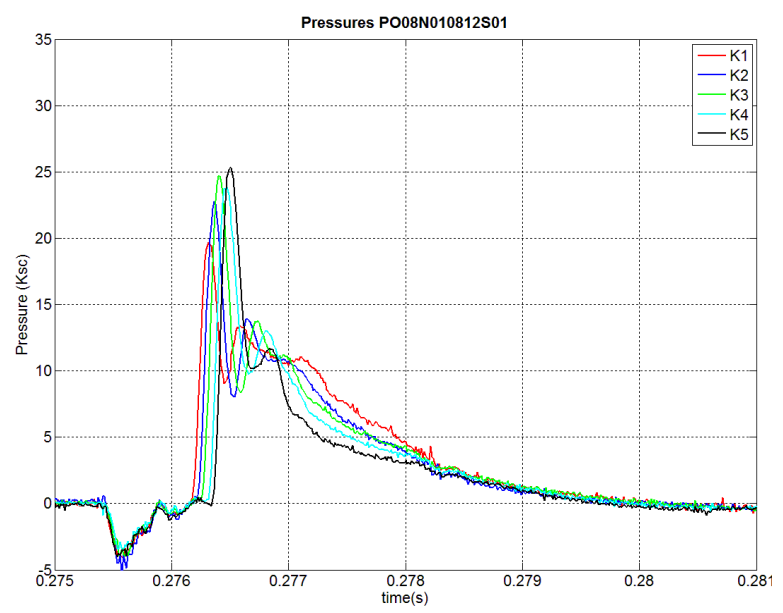

Fig.8. ER 0.8 without DDT device 
International Journal of Recent advances in Mechanical Engineering (IJMECH) Vol.3, No.3, August 2014

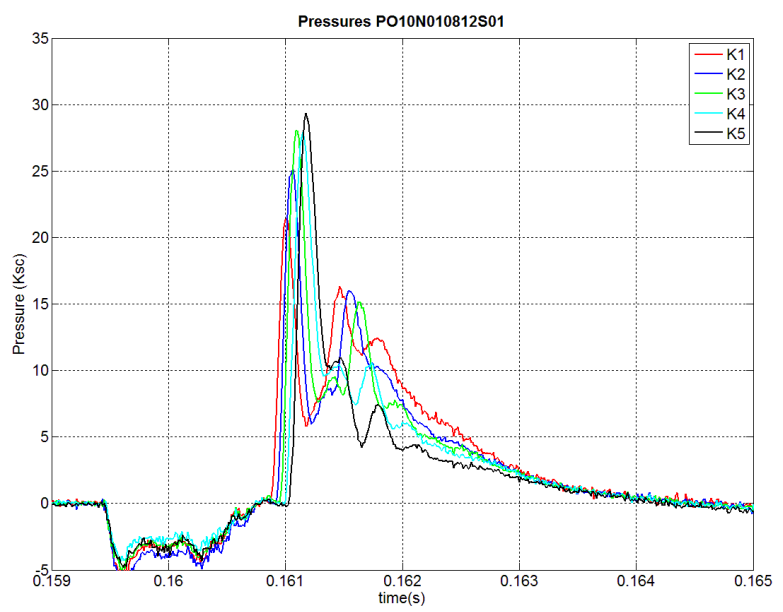

Fig.9 ER 1.0 without DDT device

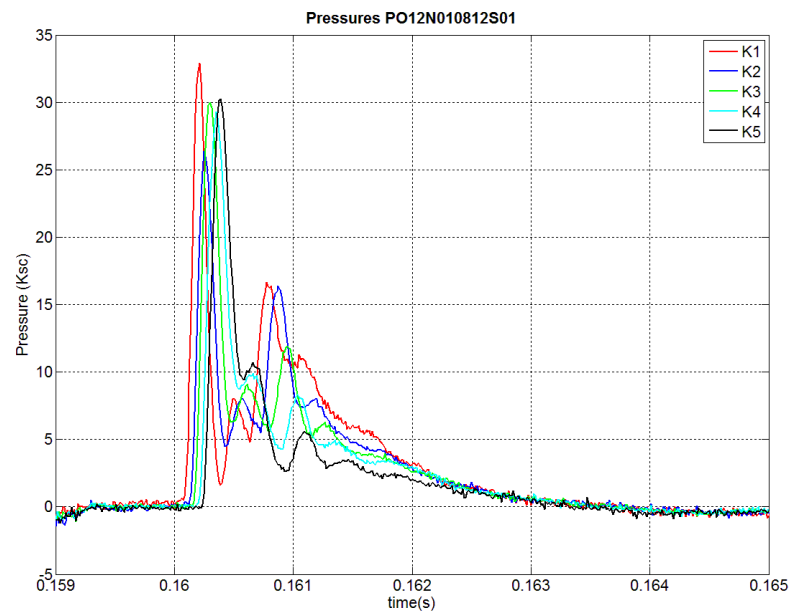

Fig.10. ER 1.2 without DDT device

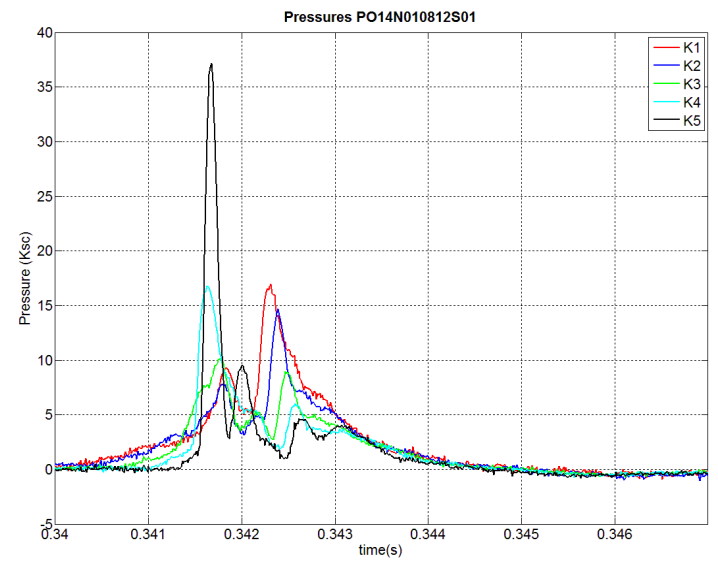

Fig.11. ER 1.4 without DDT device 


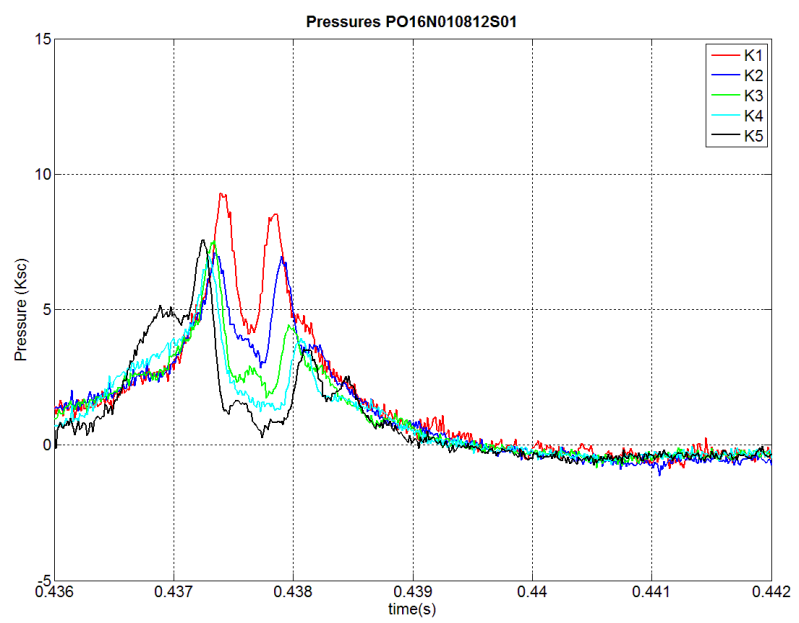

Fig.12. ER 1.6 without DDT device

\section{[1]. Remarks on Tests without DDT}

1. From the graphs it is evident that detonation is achieved.

2. With 0.8 Equivalence Ratio (ER) the peak pressures recorded are around $25 \mathrm{Ksc}$. The maximum pressure recorded in K5 PT which is located at $650 \mathrm{~mm}$ from head end of injector, which means that the detonation distance is around $650 \mathrm{~mm}$ which is very high.

3. With 1.0 Equivalence Ratio (ER) the peak pressures recorded are around $29 \mathrm{Ksc}$. The maximum pressure recorded in K5 PT which is located at $650 \mathrm{~mm}$ which means that the detonation distance is around $650 \mathrm{~mm}$ which is very high.

4. With 1.2 Equivalence Ratio (ER) the peak pressures recorded are around $33 \mathrm{Ksc}$. The maximum pressure recorded in K1 PT which is located at $250 \mathrm{~mm}$ which means that the detonation distance is around $250 \mathrm{~mm}$ which is close to the expected value from the literature.

5. With 1.4 Equivalence Ratio (ER) the peak pressures recorded are around $37 \mathrm{Ksc}$. The maximum pressure also recorded in K5 PT which is located at $650 \mathrm{~mm}$ and the shock wave was not sustaining. The detonation was not continuing.

6. With 1.6 Equivalence Ratio (ER) the peak pressures recorded are around $9 \mathrm{Ksc}$. From the graph it is clear that there was no proper detonation action inside the tube.

\section{B. Experiments with DDT (Shchelkin Sprirals)}

Second set of experiments were carried out with propane and oxygen with DDT enhancing devices. The Shchelkin Spriral is $50 \mathrm{~mm}$ in length and blockage ratio(BR) of 43\%. The following Fig. show the pressures recorded during the tests. The units of pressure $\operatorname{are~} \mathrm{Kg} / \mathrm{cm}^{2}$. Five runs were taken with ER value ranging from 0.8 to 1.6 . 
International Journal of Recent advances in Mechanical Engineering (IJMECH) Vol.3, No.3, August 2014

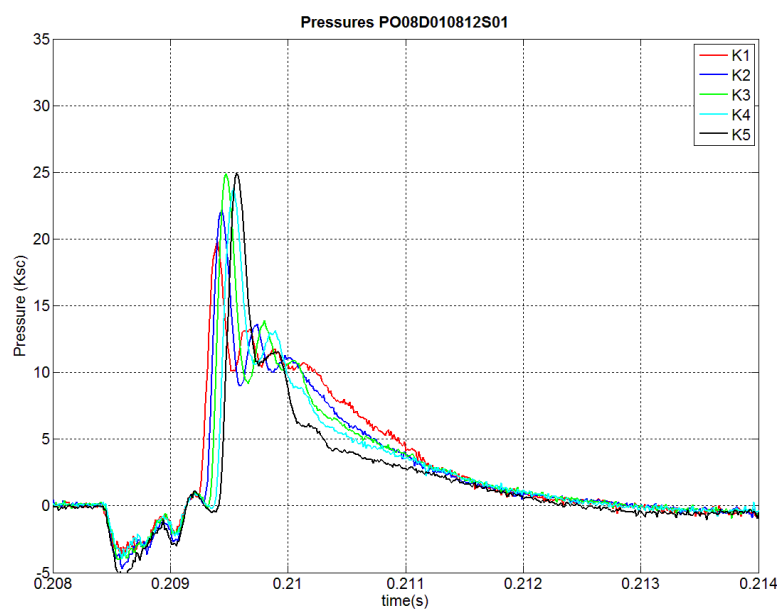

Fig.13. ER 0.8 with DDT 50mm Shchelkin Spiral

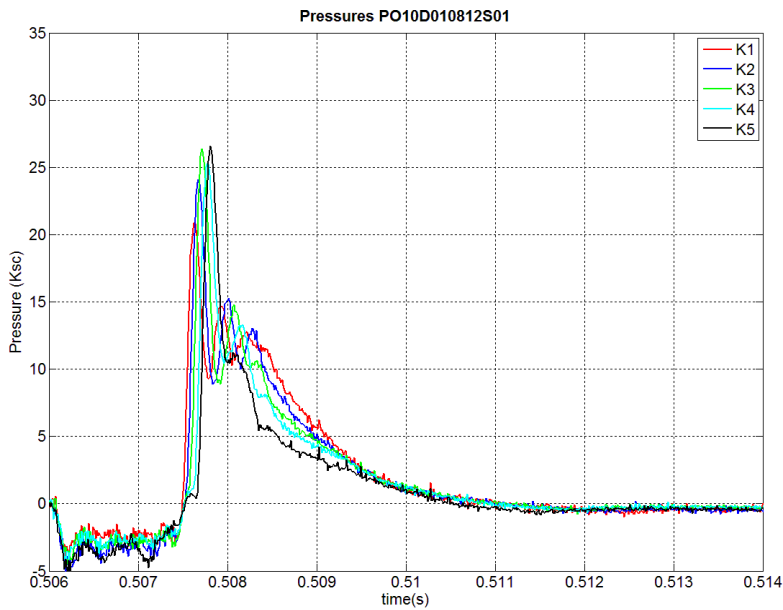

Fig.14. ER 1.0 with DDT 50mm Shchelkin Spiral

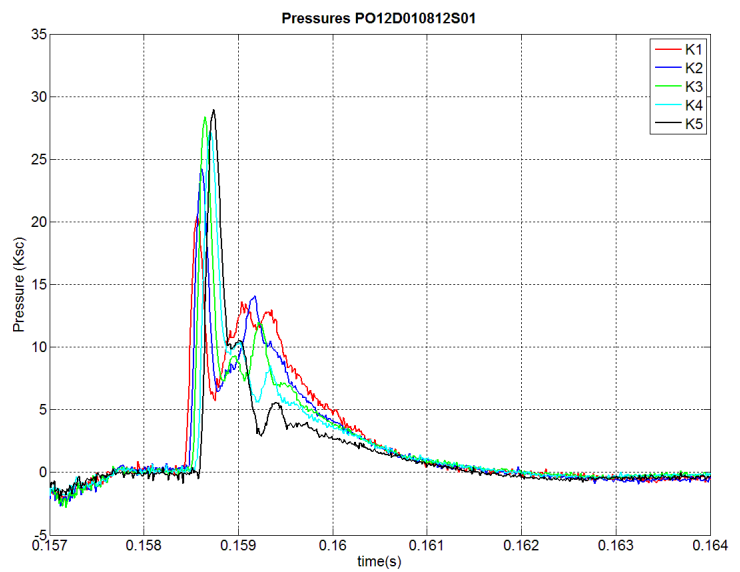

Fig.15. ER 1.2 with DDT 50mm Shchelkin Spiral 


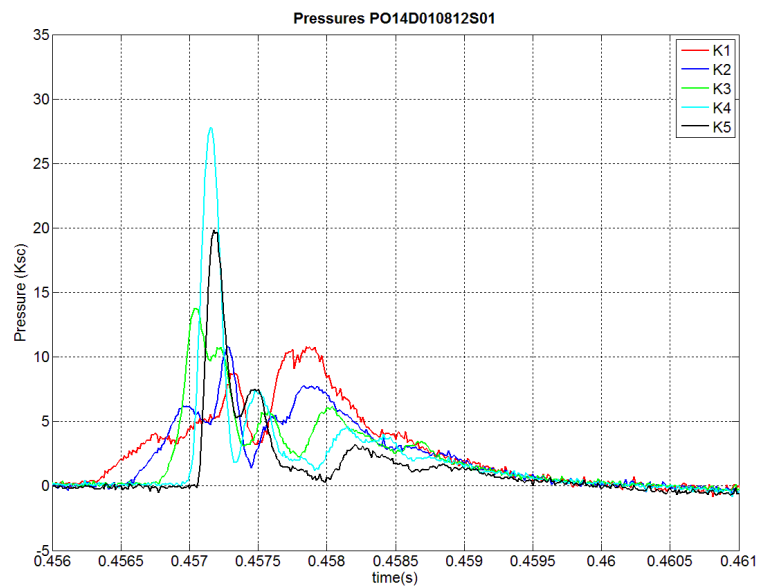

Fig.16. ER 1.4 with DDT 50mm Shchelkin Spiral

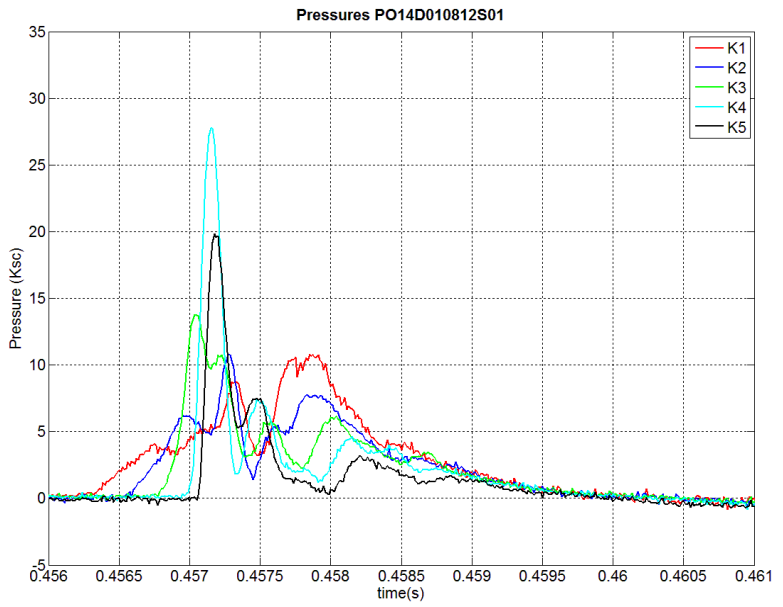

Fig.17. ER 1.6 with DDT 50mm Shchelkin Spiral

\section{[1]. Remarks on Tests with DDT device}

1.From the graphs it is evident that detonation is achieved.

2. With 0.8 Equivalence Ratio (ER) the peak pressures recorded are around $25 \mathrm{Ksc}$. The maximum pressure recorded in K5 PT similar to the tests without DDT which is located at $650 \mathrm{~mm}$ which means that the detonation distance is around $650 \mathrm{~mm}$ which is very high. No improvement is observed with placement of DDT device.

3.With 1.0 Equivalence Ratio (ER) the peak pressures recorded are around $27 \mathrm{Ksc}$ against $25 \mathrm{Ksc}$ in the test without DDT. The maximum pressure recorded in K5 PT similar to the tests without DDT which is located at $650 \mathrm{~mm}$ which means that the detonation distance is around $650 \mathrm{~mm}$ which is very high. Not much improvement is observed with placement of DDT device.

4. With 1.2 Equivalence Ratio (ER) the peak pressures recorded are around $27 \mathrm{Ksc}$ against $33 \mathrm{Ksc}$ in the test without DDT. The maximum pressure recorded in K5 PT similar to the tests without DDT which is located at $650 \mathrm{~mm}$ which means that the detonation distance is around $650 \mathrm{~mm}$ which is very high. There a deterioration observed in the detonation pressures. So placement of DDT device is not helping in any way in improving the detonation characteristics.

5. With 1.4 Equivalence Ratio (ER) the peak pressures recorded are around 27 Ksc against 37 Ksc in the test without DDT. The maximum pressure recorded in K4 PT which is located at $550 \mathrm{~mm}$ 
and the shock wave was not sustaining. The detonation shock wave was not continuing. 6. With 1.6 Equivalence Ratio (ER) no detonation was observed in the tube.

\section{CONCLUSIONS}

A series of detonation experiments were conducted using Propane+Oxygen using Dia. $25 \mathrm{~mm}$ tube. From the experiments with varying Equivalence ratio it is clear that best detonation is achieved with 1.2 ER in minimum possible DDT distance. These experiments give clear data for designing the pre detonator for two stage PDE engine.

From the experiments with varying Equivalence ratio with DDT device no significant improvement was observed in obtaining higher CJ Pressures or in reducing the DDT run up distance.

For Propane+Oxygen mixture Detonation can be achieved with minimum ignition energy and within a short distance of $300 \mathrm{~mm}$ from the injector face of the detonation tube. The experimental data was validated with the NASA CEA detonation code results for the same mixture. The data is in close match.

Work was initiated to study effect of detonation tube diameter, shape and length on detonation characteristics. Optimisation of detonation initiation energy is also a very critical parameter which required a detailed study.

\section{REFERENCES}

[1] Bussing, T.R.A. and Pappas, G., "An Introduction to Pulse Detonation Engines," AIAA 94-0263, 32nd Aerospace Sciences Meeting \& Exhibit, Reno, NV, January 10-13, 1994.

[2] Bussing, T.R.A., Hinkey, J.B., and Kaye, L., "Pulse Detonation Engine Preliminary Design Considerations," AIAA 94-3220, 30th Joint Propulsion Conference, Indianapolis, IN, June 27-29, 1994.

[3] S. Gordon, B.J. McBride, Computer Program for Calculation of Complex Chemical Equilibrium Compositions and Applications. I. Analysis, Reference Publication RP-1311, NASA (1994).

[4] Eidelman, S . and Grossmann, W., "Pulsed Detonation Engine Experimental and Theoretical Review," AIAA 92-3168, 28th AIAAIASMFJSAEIASEE Joint Propulsion Conference and Exhibit, Nashville, TN, July 64,1992.

[5] K. Kailasanath, "Applications of Detonations to Propulsion: A Review," AIAA Paper 99-1067, 37th AlAA Aerospace Sciences Meeting and Exhibit January 11 -14,1999 / Reno, NV.

[6] J.M. Austin and J.E. Shepherd, "Detonations in Hydrocarbon Fuel Blends" GALCIT Report FM99, California Institute of Technology, 2000.

[7] Francois FALEMPIN, Dominique BOUCHAUD and Bernard FORRAT, "Pulsed Detonation Engine Possible application to low cost Tactical Missile and to Space launcher," AIAA 2001-3815, 37th AIAA/ASME/SAE/ASEE Joint Propulsion Conference 8-11 July 2001 / Salt Lake City, Utah.

[8] Chao, T.W., Winterberger, E. \& Shepard, J.E., On the Design of Pulse Detonation Engines, GALCIT Report FM 00-7, California Institute of Technology, 2001.

[9] W. H. Heiser and D. T. Pratt, "Thermodynamic cycle analysis of pulse detonation engines," J. Propuls. Power, 18, No. 1, 68-76 (2002).

[10] Allgood, D., Gutmark, E., Meyer, T., Hoke, J.,Katta, V., Schauer, F. and Gord, J. R., “Computational and Experimental Studies of Pulse Detonation Engines," AIAA Paper 2003-0889, 2003.

[11] Roy, G. D., Frolov, S. M., Borisov, A. A., Netzer, D. W. Pulse Detonation Propulsion: Challenges, Current Status, and Future Perspective. Prog. Energy Combust. Sci., Vol. 30, No. 6, pp. 545-672, 2004.

[12] AIAA 2006-552, "Experimental Investigations on DDT Enhancements by Shchelkin Spirals in a PDE" by T. H. New, P. K. Panicker, F. K. Lu and H. M. Tsai

[13] Philip K. Panicker, Frank K. Lu, Donald R. Wilson, "Practical issues in ground testing of pulsed detonation engines" 2007 ASMC IMECE-22068, Seattle, USA

[14] J.E. Shepherd, "Detonation in gases", Proceedings of the Combustion Institute 32 (2009) 83-98 